\title{
PENGEMBANGAN PEMBANGKIT LISTRIK TENAGA MIKRO HIDRO TERPADU BERKELANJUTAN DI BUMIAJI - KOTA BATU
}

\section{Development of Suistainable and Intergrated Micro Hydro Power Plant in Bumiaji - Kota Batu}

\author{
Suwignyo ${ }^{1}$, Ilyas Masudin ${ }^{2}$, Ali Mokhtar ${ }^{3}$ \\ ${ }^{1}$ Jurusan Teknik Sipil-Fakultas Teknik-Universitas Muhammadiyah Malang \\ email:wignyo_08@yahoo.com \\ ${ }^{2}$ Jurusan Teeknik Industri-Fakultas Teknik-Universitas Muhammadiyah Malang \\ email: masudin@umm.ac.id \\ ${ }^{3}$ Jurusan Teknik Mesin-Fakultas Teknik-Universitas Muhammadiyah Malang \\ email: alimokhtar011@gmail.com
}

\begin{abstract}
Micro Hydro Power Plant (MHPP) is electrical technology from hydro renewable energy in small scale. Potency of micro hydro energy in Indonesia about $500.00 \mathrm{MW}$ seperatly on widearea of nusantara. This research are design of MHPP intergrate with development of rural water supply and conservation of watershed, and development of education facility of renewable energy technology. Research methods and stage of research are survey and analysis of discharge, survey and analysis of hydraulic head, design of MHPP, design of mechanicalelectrical components and drawing. Research result of MHPP Bumiaji are generating discharge $(Q) 0.25 \mathrm{~m}^{3} / \mathrm{s}$, gross hydraulic head $(H) 4.00 \mathrm{~m}$, power generating $(P) 7.28 \mathrm{~kW}$, applied of propeller turbine and the MHPP Bumiaji to support of rural water supply.
\end{abstract}

Keywords: MHPP, Propeller Turbine, Technology Education

\begin{abstract}
Abstrak
Pembangkit Listrik Tenaga Mikro Hidro (PLTMH) merupakan teknologi bidang kelistrikan dari sumber energi terbarukan hidro. Potensi energi hidro di Indonesia cukup besar dan tersebar luas di seluruh kepulauan nusantara. Teknologi PLTMH terus berkembang dan perlu terus dikembangkan serta disebarluaskan kepada masyarakat, agar pengembangan dan pemanfaatan energi terbarukan hidro semakin luas dan semakin meningkat. Penelitian bertujuan mendesain dan mengaplikasikan PLTMH yang terpadu dengan pemanfaatannya untuk penyediaan air minum perdesaan, dipadukan dengan upaya konservasi daerah aliran sungai dan pengembangan sarana wisata edukasi teknologi energi terbarukan. Metode dan tahapan penelitian meliputi survey pemilihan lokasi, pengukuran dan analisa debit pembangkit, pengukuran dan penentuan tinggi jatuh hidrolik, desain bangunan sipil, pemilihan tipe turbin dan desain pekerjaan mekanikal-elektrikal dan penggambaran desain PLTMH. Hasil penelitian PLTMH Bumiaji adalah debit pembangkit (Q) $0,25 \mathrm{~m}^{3} / \mathrm{dt}$, total tinggi jatuh hidrolik (Htotal) 4,00 m, daya terbangkit (P) 7,28 kW, tipe turbin propeller. PLTMH Bumiaji di manfaatkan untuk mendukung penyediaan air minum perdesaan, sebagai sarana wisata edukasi teknologi energi terbarukan dan diintregasikan dengan upaya konservasi daerah aliran sungai.
\end{abstract}

Kata kunci: PLTMH, Turbin Tubular, Wisata Edukasi Teknologi

\section{PENDAHULUAN}

Pembangunan Pembangkit Listrik Tenaga Mikro Hidro (PLTMH) di Indonesia terus berkembang dan potensi sumber daya air yang dapat dimanfaatkan untuk mikrohidro cukup besar tersebar luas di seluruh nusantara. Potensi mikrohidro yang sudah terinventarisasi mencapai lebih 500,00 MW (IMIDAP, 2008), berupa potensi mikrohidro di sungai dan mata air, belum termasuk potensi di jaringan irigasi teknis yang tersebar di Jawa, Sumatera, Bali dan Sulawesi serta jaringan-jaringan irigasi di pulau-pulau seluruh Indonesia. Untuk terus mendukung pengembangan teknologi mikrohidro dan berdasarkan pengalaman perencanaan dan pembangunan PLTMH diantaranya : Pengembangan PLTMH 
Sumbermaron (Irfan, M, dkk, 2012), PLTMH Sengkaling 2 UMM (Suwignyo, 2014) dan hasil penelitian turbin propeller poros horizontal (Suwignyo, 2015), maka dilakukan penelitian Pengembangan PLTMH Terpadu dan Beerkelanjutan.

Penelitian bertujuan menghasilkan produk desain PLTMH Bumiaji untuk mendukung penyediaan air minum perdesaan yang dipadukan dengan program konservasi Daerah Aliran Sungai (DAS) agar kelestarian sumber air lestari, sehingga berkelanjutan dan diselaraskan dengan pengembangan sarana wisata edukasi sains-teknologi terapan enrgi terbarukan hidro.

\section{METODE PENELITIAN}

Kegiatan penelitian meliputi langkah dan tahapan berikut :

- Survey sosial-ekonomi masyarakat pemanfaat air minum.

- Suvey, pengukuran debit aliran sungai.

- Survey pengukuran dan pemetaan topografi.

- Analisa kebutuhan air minum, analisa debit andalan pembangkit dan analisa tinggi jatuh hidrolik.

- Proses desain PLTMH Bumiaji terdiri dari desain bendung, desain pintu pengambilan, desain saluran pembawa/ head race, desain kolam penampung, desain pipa penghantar/ penstock, desain rumah pembangkit dan desain saluran pembuang/ tailrace.

- Proses desain mekanikal dan elektrikal terdiri dari pelihan tipe turbin dan desain turbin, perhitungan dan pemihan generaton, desain control elektrik, desain jaringan kelistrikan dan pelihan dan perhitungan pompa air.

- Penggambaran hasil desain pekerjaan sipil, pekerjaan mekanikal, pekerjaan elektrikal dan penataan kawasan/ lingkungan PLTMH.

Pengembangan desain PLTMH Bumiaji diselaraskan dengan desain konservasi DAS, khususnya konservasi sepadan sungai dengan tanaman bambu dengan melestarikan tanaman bambu yang sudah ada dan mengembangkan tanaman bambu baru disepanjang jalur sepadan sungai di hulu. Desain konservasi DAS juga merancang pertanian dengan sistem tersring dan konsep budidaya pertanian hemat air dan konsep pengurangan limpasan permukan serta mereduksi erosi permukaan tanah.

Analisa sosial-ekonomi masyarakat pemanfaat air untuk menentukan tingkat kebutuhan air, menentukan tarif air dan kemampuan bayar iuran air, menentukan debit kebutuhan pemompaan air. Sedang analisa debit air untuk menentukan debit andalan dan debit pembangkit PLTMH, debit andalan pembangkit ditetapkan dengan tingkat keandalan $90 \%$. Pengkuran dan dan pemetaan lokasi dilakukan untuk mendukung analisa desain tata-letak dan menentukan potensi tinggi jatuh hidrolik untuk pembangkit. Proses desain bangunan air (bendung, pintu pengambilan, saluran pembawa, kolam penampung dan saluran pembuang) didasarkan Standar Perencanaan Irigasi-Kriteria Perencana (DPU-Dirjen SDA, 2008). Sedangkan proses desain pekerjaan mekanikal dan elektrikal didasarkan pada Pedoman Teknis Standarisasi Peralatan dan Komponen PLTMH (IMIDAP, 2008). Semua hasil pengukuran, analisa data dan desain pekerjaan sipil dan pekerjaan mekanikalelektrikal dituangkan dalam produk gambar desain yang dapat digunakan sebagai proses berikutnya yaitu pelaksanaan pembangunan konstruksi PLTMH dan sebagai bagian dari dasar operasional dan pemeliharaan pasca konstruksi.

\section{HASIL DAN PEMBAHASAN}

Hasil survey, analisa dan desain PLTMH Bumiaji dan desain konservasi DAS sebagai berikut :

- Kebutuhan air minum untuk 50 keluarga dengan tingkat konsumsi 100 ltr/Org/hari adalah $0,43 \mathrm{ltr} / \mathrm{dt}$, durasi kerja pompa 16 jam per hari.

- Berdasarkan pengukuran dan analisa debit (Qp) dengan keandalan $90 \%$ adalah 0,25 $\mathrm{m}^{3} / \mathrm{dt}$. Sedangkan dari hasil pengukuran, pemetaan topografi dan desain tata-letak ditentukan tinggi jatuh hidrolik (Htotal) adalah 4,00 m.

- Pemilihan tipe turbin secara grafis didasarkan pada $\mathrm{Qp}=0,25 \mathrm{~m}^{3} / \mathrm{dt}$ dan Hgross $=4,00 \mathrm{~m}$ sebagai berikut : 


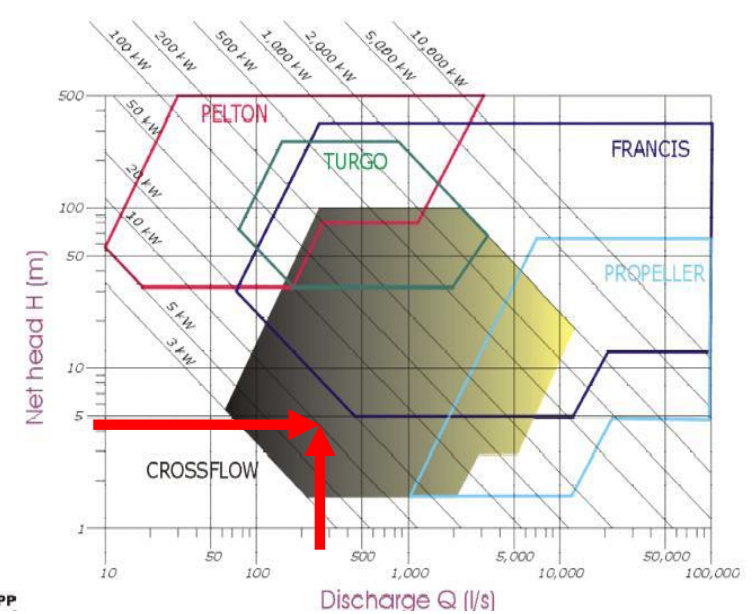

Gambar 1. Pemilihan tipe turbin secara grafis

Dengan kriteria nilai debit dan tinggi jatuh hidrolik tersebut, tipe turbin yang sesuai adalah turbin crossflow (gambar 1), tetapi dekat kesesuaian dengan turbin propeller. Dan untuk menambah dan mengembangkan kemampuan desain dan pembuatan turbin, maka dipilih menggunakan turbin propeller.

- Daya terbangkit yang dihasilkan adalah :

$$
\mathrm{P}=9.81 \times \mathrm{Q} \times \mathrm{H} \times \eta_{\mathrm{t}} \times \eta_{\text {gen }}
$$

Dimana :

$\mathrm{Q}=$ debit air, m3/detik $(0,25 \mathrm{~m} 3 / \mathrm{dt})$

$\mathrm{H}=$ efektif head, $\mathrm{m}(4,00 \mathrm{~m})$

$\eta_{\mathrm{t}}=$ efisiensi turbin $=0.90$ untuk turbin propeller

$\eta_{\text {gen }}=$ efisiensi generator $(0.90)$

$\mathrm{P}=9.81 \times 0,81 \times 0,25 \times 3,84$ $=7,28 \mathrm{~kW}$.

- Desain bangunan sipil meliputi :

- Bendung tetap pasangan batu tinggi $2,00 \mathrm{~m}$, lebar bendung $4,00 \mathrm{~m}, 1$ (satu) buah pintu pengambilan lebar $0,60 \mathrm{~m}$.

- Saluran pembawa panjang 150,00 m, kedalaman aliran 0,28 m, lebar 0,90 m, kecepatan aliran 0,99 $\mathrm{m} / \mathrm{dt}$.

- Kolam penampung lebar 4,00 m, panjang $6.30 \mathrm{~m}$ dan kedalaman 3,60 $\mathrm{m}$.

- Rumah pembangkit lebar 4,00 m, panjang 4,00 $\mathrm{m}$ dan bangunan 1 (satu) lantai, gambar 2.

- Saluran pembuang dimensi sama dengan saluran pembawa.

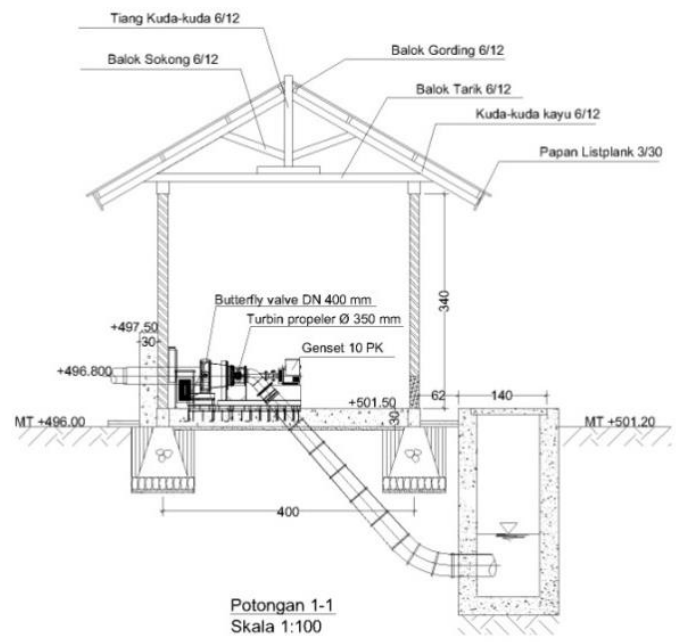

Gambar 2. PLTMH Bumiaji kapasitas 7,28 kWatt

- Desain mekanikal-elektrikal untuk turbin tipe propeller dengan kapasitas debit pembangkit $\mathrm{Qp}=0,25 \mathrm{~m}^{3} / \mathrm{dt}$ dan tinggi jatuh hidrolik Htotal $=4,00 \mathrm{~m}$, sedangkan desai generator sinkron 3 phase kapasitas 10 kVA, serta komponen kontrol elektrik untuk kontrol frekuensi, tegangan dan daya dengan kapasitas $10 \mathrm{kVA}$.

- Kapasitas pompa didesain untuk tinggi pemompaan 50,00 m dengan kapasitas daya 7,00 kWatt, mampu memompa air dengan debit sekitar $10 \mathrm{ltr} / \mathrm{dtk}$.

- Desain konservasi DAS, titik fokusnya pada pelestarian tanaman bambu yang sudah ada dan pengembangan tanaman bambu baru sepanjang kiri-kanan sepadan sungai. Dan desain dan penerapan budidaya pertanian hemat air dan mereduksi erosi, gambar 3.

Dengan kapasitas pompa $10 \mathrm{ltr} / \mathrm{dt}$ dan debit kebutuhan air minum hanya $0,43 \mathrm{ltr} / \mathrm{dt}$ dan sumber air bersih cukup tersedia, maka dipertimbangkan untuk memanfaatkan kapasitas sisa sebagai sumber air irigasi pancar (sprinkler irrigation) untuk mendukung budidaya tanam pertanian bernilai ekonomi tinggi. Pertanian dengan jaringan irigasi pancar akan sejalan dengan program Pemerintah Kota Batu dalam upaya pengembangan pariwisata berbasis agro dan edukasi lingkungan. 


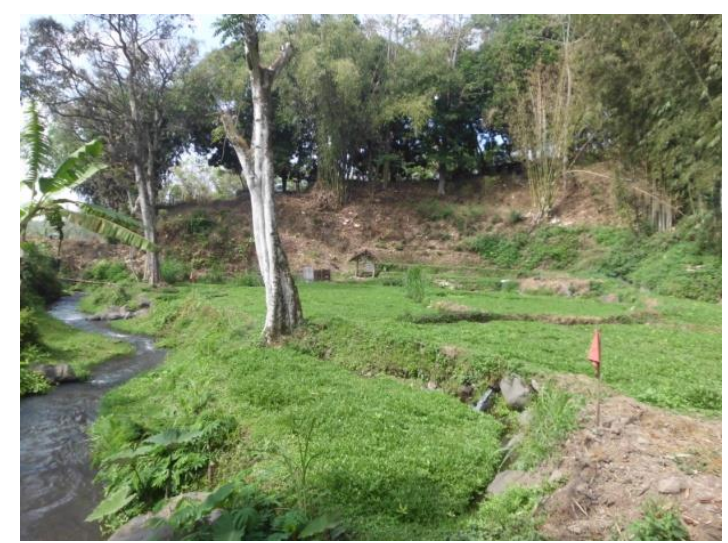

Gambar 3. Kawasan konservasi sepadan sungai

\section{KESIMPULAN DAN SARAN}

\section{Kesimpulan}

Dari survey, pengukuran, analisa data, desain dan penggambaran, maka disimpulkan sebagi berikut :

- Kebutuhan air minum perdesaan 0,43 ltr/ dtk.

- Debit andalan untuk pembangkit dengan probabilitas keandalan $90 \%$ adalah 0,25 $\mathrm{m}^{3} / \mathrm{dt}$.

- Berdasarkan hasil pengukuran topografi dan desain tata-letak, maka tinggi jatuh hidrolik adalah 4,00 m.

- Daya terbangkit PLTMH Bumiaji 7,28 $\mathrm{kW}$.

- Turbin terpilih tipe turbin propeller.

- Generator 3 phase, kapasitas $10 \mathrm{~kW}$.

- Produksi listrik PLTMH Bumiaji untuk memompa air minum 0,43 ltr/dt dan rencana pemompaan 9, $57 \mathrm{ltr} / \mathrm{dt}$ untuk irigasi pancar (sprinkler irrigation).

\section{Saran}

Hasil penelitian ini selayaknya dilanjutkan dengan tindakan aplikasi dengan membangun PLTMH Bumiaji yang dipadukan dengan kegiatan konservasi DAS, sehingga dapat dimanfaatkan untuk mendukung suplai air minum masyarakat perdesaan dan sebagai sarana wisata edukasi sains-teknologi serta konservasi sumber daya alam khususnya daerah aliran sungai.

\section{DAFTAR PUSTAKA}

2008. Standar Perencanaan Irigasi Kp-02, KP-03 dan KP-04. Edisi ke 2. Jakarta : Direktorat Jenderal Sumber
Daya Air, Departemen Pekerjaan Umum

IMIDAP. 2008. Pedoman Teknis Standarisasi Peralatan dan Komponen PLTMH. Edisi ke 1. Jakarta : Direktorat Jenderal Listrik Dan Pemanfaatan Energi, Departemen Energi Dan Sumber Daya Mineral

Irfan, M, dkk. 2012. Pengembangan PLTMH Sumbermaron. Malang : Fakultas Teknik Universitas Muhammadiyah Malang

Suwignyo, 2014, Desain Turbin, Pabrikasi Turbin Dan Pembangunan Pltmh Untuk Mendukung Sistem Penyediaan Air Minum Perdesaan, Prosiding Seminar Nasional Teknologi Terapan UGM, Hal 478, Yogjakarta, Indonesia Suwignyo. 2014. Studi Kelayakan dan Detail Desain PLTMH Sengkaling 2. Malang : Universitas Muhammadiyah Malang Suwignyo, Ilyas Masudi dan Mulyono. 2015.

Pengembangan Energi TerbarukanPembangkit Listrik Tenaga Mikro Hidro: Perancangan Dan Pabrikasi Turbin Hidro Poros Horisontal Dengan Fixed Guide Vane (FGV) Untuk Mendukung Industri PLTMH. Malang : Direktorat Penelitian Dan Pengabdian Pada Masyarakat (DPPM) Universitas Muhammadiyah Malang 